\title{
Analisis Sebaran Spasial Pengemis Di Kawasan Sanglah Denpasar
}

\author{
Aprilia Riszi Indah Dewi Shara, Umi Listyaningsih, Sri Rum Giyarsih
}

Masuk: 17092019 / Diterima: 28102019 / Dipublikasi: 31122019

(c) 2019 Fakultas Hukum dan IImu Sosial UNDIKSHA dan IGI

\begin{abstract}
This study aims to analyze the spatial distribution of beggars in Sanglah. This research is a descriptive survey research with a quantitative approach based on primary data analysis. The technique used is plotting using GPS at points of location that are objects of begging. The approach used is the spatial approach. The results showed that there were several clusters in the Sanglah Region, which were used as begging locations. The clusters are in the form of settlement areas, department store, health service facilities, and religious facilities. In some patterns, some beggars have different coverage areas from one beggar to another beggar. Based on the distribution patterns, there are three forms of distribution patterns that are abstracted in the form of beggar travel routes in the region. Each route has a center, namely Gajah Mada, Diponegoro, and Teuku Umar Dept. Store.
\end{abstract}

\section{Key words: Spatial Distribution; Beggars; Sanglah Region}

\begin{abstract}
Abstrak Penelitian ini bertujuan untuk menganalisis sebaran spasial pengemis di Kawasan Sanglah. Penelitian ini merupakan penelitian survei deskriptif dengan pendekatan kuantitatif yang berbasis pada analisis data primer. Teknik yang dipergunakan adalah plotting menggunakan GPS pada lokasi yang menjadi objek mengemis. Pendekatan yang dipergunakan adalah pendekatan keruangan. Hasil penelitian menunjukkan terdapat beberapa klaster di Kawasan Sanglah yang dijadikan sebagai lokasi mengemis. Klaster-klaster tersebut berupa kawasan permukiman, pertokoan, perdagangan, fasilitas pelayanan kesehatan, dan sarana ibadah. Pada beberapa pola, beberapa pengemis memiliki cakupan wilayah yang berbeda antara satu pengemis dengan pengemis lainnya. Berdasarkan pola sebarannya, terdapat tiga bentuk pola sebaran yang diabstraksikan dalam bentuk rute perjalanan pengemis di kawasan tersebut. Masing-masing rute memiliki pusat, yaitu Pertokoan Gajah Mada, Pertokoan Diponegoro, dan Pertokoan Teuku Umar.
\end{abstract}

Kata kunci : Sebaran Spasial; Pengemis; Kawasan Sanglah

\section{Pendahuluan}

Fenomena keberadaan pengemis di wilayah perkotaan memang bukanlah isu baru dalam sebuah pembangunan. Namun demikian, keeksistensian mereka juga penting untuk diperhatikan. Hal ini mengandung makna bahwa kebijakan terhadap penanganan pengemis juga berkontribusi terhadap eksis tidaknya mereka di suatu wilayah. Berkenaan dengan hal itu, pada umumnya fenomena keberadaan pengemis terjadi di kota-kota metropolitan yang memiliki perkembangan pesat, salah satunya terjadi di Kota Denpasar.

Aprilia Riszi Indah Dewi Shara, Umi Listyaningsih, Sri Rum Giyarsih

Fakultas Geografi, Universitas Gadjah Mada apriliariszi@gmail.com
Denpasar merupakan jantung kota Provinsi Bali yang terletak di bagian selatan Pulau Dewata. Berdasarkan data dari BPS Kota Denpasar, luas wilayah kota tersebut adalah sebesar $12.778 \mathrm{Ha}$ atau $2,27 \%$ dari luas wilayah Pulau Bali. Sementara, jumlah penduduknya mencapai 914.300 jiwa hingga tahun 2017 (BPS Kota Denpasar, 2017). Perbandingan antara luas wilayah dengan jumlah penduduk di Kota Denpasar ini benar-benar melampaui dari daya dukung wilayahnya karena pada dasarnya, dengan luas wilayah yang dimiliki Kota Denpasar, daya tampung penduduk ideal di kota tersebut hanyalah berkisar 200.000 -250.000 penduduk. Hal ini juga didukung oleh data dari hasil penelitian yang dilakukan oleh (Sriartha, Diatmika, \& Putra, 2017) yang menyatakan bahwa 
jumlah penduduk untuk semua kecamatan di Kota Denpasar melampaui jumlah penduduk optimal. Angka keterlampauan jumlah penduduk terhadap jumlah penduduk optimal yang terjadi di Kota Denpasar sangat signifikan yaitu lebih besar dari 140 ribu jiwa penduduk.

$$
\text { Pengemis di Kota Denpasar }
$$
umumnya sama dengan pengemispengemis lain yang ada di kota-kota besar Indonesia. Mereka biasa terlihat mangkal di pusat-pusat keramaian, sudut lampu merah, tempat ibadah, permukiman, dan lokasi-lokasi lainnya yang dianggap strategis. Distribusi pengemis di Kota Denpasar didominasi oleh para pengemis yang berasal dari Dusun Muntigunung di Desa Tianyar Barat dan Dusun Pedahan di Desa Tianyar Tengah, Kabupaten Karangasem (lqbali, 2005). Namun demikian, dengan semakin berkembangnya Kota Denpasar, pengemis di kota tersebut juga semakin bervariatif. Tidak hanya dari Dusun Muntigunung yang memang terkenal sebagai dusun pengemis di Bali, tetapi juga pengemis dari luar Pulau Bali pun mulai bermunculan di Kota Denpasar.

Sementara itu, dengan status Kota Denpasar sebagai ibukota provinsi, tentu pembangunan di segala bidang akan terfokus di kota ini. Cermin dari wajah Pulau Bali ternilai dari bagaimana Kota Denpasar itu sendiri. Selain berfungsi sebagai ibukota, Denpasar juga memiliki fungsi lain sebagai kota pintar yang berwawasan budaya dan berlandaskan Tri Hita Karana sebagai falsafah hidup. Denpasar juga mengemban fungsi sebagai destinasi pariwisata Bali. Hal ini secara eksplisit tertuang dalam visi misi Kota Denpasar yang terdapat dalam Perda Kota Denpasar Nomor 5 Tahun 2016 tentang RPJMD Semesta Berencana Kota Denpasar Tahun 2016 - 2021. Mengacu pada fungsi-fungsi tersebut, tentu kehadiran pengemis di Kota Denpasar tidaklah tepat.

Kontradiksi keberadaaan pengemis di Kota Denpasar memberi makna bahwa penelitian ini penting untuk dilakukan. Bagian penting lain yang menjadi acuan adalah perlunya eksplorasi dalam mengidentifikasi karakteristik ruang (lokasi) mengemis. Hal ini karena berbicara mengenai pengemis adalah berbicara tentang kompleksitas. Lokasi memiliki peranan yang cukup besar dalam menganalisis sebab-sebab ketertarikan mereka mengemis di kota tersebut.

Oleh karena itu, dalam hal ini Kawasan Sanglah Kota Denpasar dipilih sebagai fokus lokasi penelitian. Kawasan Sanglah berdasarkan Perda Kota Denpasar Nomor 27 Tahun 2011 tentang RTRW Kota Denpasar Tahun 2011 -2031 dalam pasal 15 tentang sistem pusatpusat pelayanan kota, merupakan kawasan dengan fungsi sebagai pusat kegiatan ekonomi, pendidikan tinggi, dan pelayanan kesehatan skala wilayah. Oleh karena fungsi tersebut, maka Kawasan Sanglah merupakan kawasan paling strategis di Kota Denpasar untuk dijadikan sebagai daerah tujuan para pengemis. Hal ini tentu diperkuat oleh beberapa hasil penelitian sebelumnya yang menyatakan bahwa pengemis di Kota Denpasar umumnya berkeliaran di sekitar Jalan Diponegoro, Monang-Maning, Imam Bonjol, dan sekitarnya (Aprilia, 2015). Ruas-ruas jalan tersebut merupakan bagian dari Kawasan Sanglah Kota Denpasar. Penelitian-penelitian sebelumnya terkait dengan fenomena pengemis lebih banyak menitikberatkan pada tinjauannya tentang aspek sosial (Anggriana \& Noviyanti, 2016; Iqbali, 2006; Yuniarti, 2012) dan strategi bertahan hidup (Ahmad, 2012; Fu'adah, Astuti, \& Utomo, 2017; Zukna, Pribadi, \& Nopianti, 2018). Sangat sedikit, bahkan belum dijumpai penelitian tentang pengemis yang ditinjau menggunakan pendekatan geografi. Berdasarkan penjabaran tersebut, tinjauan terkait penelitian ini difokuskan pada analisis sebaran ruang (lokasi) mengemis pengemis di Kawasan Sanglah, Denpasar yang merupakan bagian dari pendekatan geografi.

\section{Metode}

Metode yang digunakan dalam penelitian ini yakni metode survei dengan pendekatan kuantitatif. Analisis geografi yang dipergunakan adalah dengan pendekatan keruangan dengan analisis pola keruangan. Sebaran spasial pengemis diolah dengan tiga tahapan. 
Tahap pertama, yakni dengan menggunakan data sekunder dari Dinas Sosial terkait sebaran pengemis di Kota Denpasar. Data dari Dinas Sosial ini selanjutnya akan dituangkan dalam bentuk peta sehingga dapat diketahui secara garis besar terkait sebaran pengemis di Kota Denpasar. Tahap kedua adalah melakukan plotting di lapangan terhadap pengemis yang ada di Kawasan Sanglah. Tahap ketiga adalah melakukan regionalisasi kawasan sesuai dengan fungsi kawasannya. Kawasan yang diregionalisasi dalam hal ini adalah Kawasan Sanglah. Hasil plotting akan diabstraksikan ke dalam sebuah peta, sehingga akan diperoleh karakteristik dari pengemis secara ruang.

Alasan pemilihan lokasi dari penelitian ini didasari pada tiga hal, yakni: (1) Berdasarkan Perda RTRW Kota Denpasar, Kawasan Sanglah merupakan pusat kegiatan ekonomi, pendidikan tinggi, dan pelayanan kesehatan skala wilayah (Pasal 15 ayat 2 Perda Kota Denpasar Nomor 27 Tahun 2011); (2) Kawasan Sanglah merupakan kawasan strategis yang memiliki kepentingan untuk pelayanan sosial dan publik yang tinggi (Pasal 61 ayat 5 Perda Kota Denpasar Nomor 27 Tahun 2011); dan (3) Data dari Dinas Sosial dan Tenaga Kerja Kota Denpasar menunjukkan bahwa persebaran pengemis di Kota Denpasar sebagian besar berada di Kawasan Sanglah. Peta lokasi penelitian seperti terlihat pada Gambar 1.

\section{Hasil dan Pembahasan}

\section{Sebaran Spasial Pengemis di Kawasan Sanglah}

Sebaran spasial pengemis di Kawasan Sanglah menjelaskan beberapa hal, diantaranya rute perjalanan pengemis, objek-objek kunjungan, dan juga waktu kunjungan. Hasil olah data yang didapat mengacu pada observasi dan data dari Dinas Sosial Kota Denpasar. Berdasarkan hasil interview dengan pihak Dinas Sosial Kota Denpasar, salah satu kegiatan rutin yang diadakan adalah melakukan razia untuk mengurangi jumlah pengemis. Razia pengemis dilakukan dua kali dalam satu minggu, setiap hari Senin dan Selasa atau Rabu yang bekerjasama dengan Satpol PP Kota Denpasar. Berdasarkan hasil razia, objek-objek kunjungan pengemis paling banyak berada di Kecamatan Denpasar Barat. Kecamatan Denpasar Barat sendiri memang merupakan sentral pertumbuhan wilayah di Kota Denpasar. Shara (2018) dalam studinya tentang Analisis Konektivitas Wilayah di Kota Denpasar menyebutkan bahwa berdasarkan indeks sentralitasnya, Kecamatan Denpasar Barat menempati indeks tertinggi sehingga dijadikan sebagai hirarki I. Indeks sentralitas ini diukur dengan mengacu pada keberadaan sarana dan prasarana di masing-masing kecamatan di Kota Denpasar. Semakin banyak dan lengkapnya fasilitas di suatu wilayah, juga dapat menjadi tolok ukur perkembangan wilayah bersangkutan (di luar pertimbangan jumlah penduduk di masing-masing kecamatan).

Shara (2018) juga menjelaskan bahwa penempatan Kecamatan Denpasar Barat sebagai hirarki I adalah tepat dan sesuai. Hal ini karena secara fungsional, Kecamatan Denpasar Barat memegang peranan penting, yakni sebagai pusat pemerintahan, pusat kegiatan ekonomi, pendidikan tinggi, dan juga pusat pelayanan kesehatan. Oleh karena faktorfaktor inilah, Kecamatan Denpasar Barat memiliki pengaruh yang paling kuat diantara kecamatan-kecamatan lain di Kota Denpasar. Keberadaan Pasar Badung sebagai sentral pasar tradisional di Kota Denpasar, RSUP Sanglah sebagai sentral rumah sakit di Kota Denpasar, Universitas Udayana sebagai Perguruan Tinggi Negeri yang paling populer, Lapangan Puputan sebagai salah satu RTH kota yang letaknya berdampingan dengan patung Catur Muka (titik nol Kota Denpasar), merupakan sebagian kecil dari contoh hirarki Kecamatan Denpasar Barat sebagai hirarki I. 
Analisis Sebaran Spasial Pengemis Di Kawasan Sanglah Denpasar/ Aprilia Riszi Indah Dewi Shara, Umi Listyaningsih, Sri Rum Giyarsih

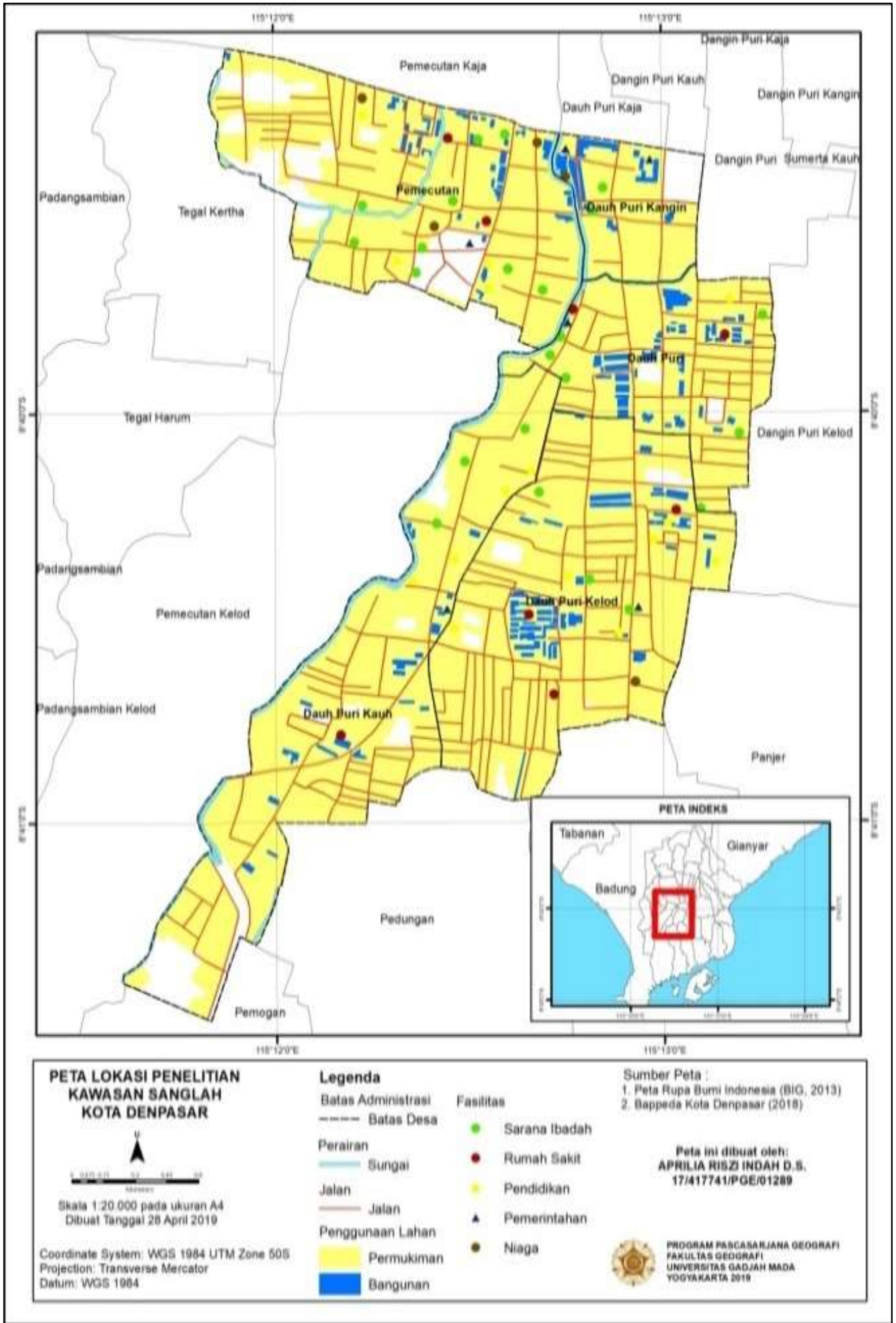

Gambar 1. Peta Lokasi Penelitian 
Belum lagi pusat pemerintahan kota juga berada di kecamatan ini, menambah kekuatan Kecamatan Denpasar Barat sebagai kecamatan dengan status hirarki I.

Selain itu, berdasarkan analisis gravitasi juga menunjukkan bahwa Kecamatan Denpasar Barat memiliki nilai interaksi tertinggi mencapai 41.404.680.725 dibanding tiga kecamatan lainnya di Kota Denpasar. Selain menunjukkan nilai interaksi tertinggi di suatu wilayah, hasil penghitungan model gravitasi tersebut juga dapat menunjukkan wilayah mana yang memiliki kedudukan sebagai pusat dan wilayah mana yang memiliki kedudukan sebagai hinterland. Berdasarkan hal tersebut, Kecamatan Denpasar Barat menduduki sebagai pusat wilayah dan sisanya, tiga kecamatan lainnya yakni Kecamatan Denpasar Utara, Timur, dan Kecamatan Denpasar Selatan sebagai hinterland di Kota Denpasar. Berdasarkan penjelasan tersebut, maka sudah sangat wajar apabila Kecamatan Denpasar Barat memiliki daya tarik tersendiri bagi pengemis.

Secara spesifik, salah satu objek kunjungan pengemis di Kecamatan Denpasar Barat paling ramai berada di Kawasan Sanglah dan sekitarnya. Pengemis akan cenderung memilih lokasilokasi yang strategis, yang mana antara lokasi keramaian satu dengan lainnya tidak berjauhan. Hal ini dapat ditemui di Kawasan Sanglah dan sekitarnya. Pasar (tradisional dan modern), kompleks pertokoan, permukiman, sarana ibadah, warung/ rumah makan, fasilitas kesehatan (rumah sakit, laboratorium klinik, apotek), sekolah, kampus/ perguruan tinggi, seluruhnya berada dalam area yang saling berdekatan.

Berdasarkan Peraturan Daerah Kota Denpasar Nomor 27 Tahun 2011 tentang Rencana Tata Ruang Wilayah Kota Denpasar Tahun 2011-2031, dalam pasal 15 tentang sistem pusat-pusat pelayanan kota, disebutkan bahwa Kawasan Sanglah dan sekitarnya memiliki fungsi sebagai pusat kegiatan ekonomi, pendidikan tinggi, dan pelayanan kesehatan skala wilayah. Selain itu, pada Bab VI tentang Penetapan Kawasan Strategis Kota pada Pasal 61 ayat (5) huruf c dijelaskan bahwa Kawasan Sanglah ditetapkan sebagai kawasan strategis yang memiliki kepentingan untuk pelayanan sosial dan publik yang tinggi. Arah pengelolaan Kawasan Sanglah sebagaimana dimaksud dalam pasal tersebut salah satunya yakni pengembangan Kawasan Sanglah dan sekitarnya sebagai salah satu pusat utama kota dengan adanya pusat pelayanan publik di kawasan tersebut seperti Universitas Udayana, Pasar Sanglah, dan Rumah Sakit Umum Pusat (RSUP) Sanglah.

Kawasan Sanglah secara fungsi dan letak memiliki nilai strategis tinggi sehingga mampu menarik pengemis untuk mengemis di kawasan tersebut. Kawasan Sanglah sendiri apabila dikaitkan dengan teori pertumbuhan wilayah, maka faktor yang menyebabkan pertumbuhan di kawasan tersebut dipengaruhi oleh faktor internal (dari wilayah itu sendiri).

Menurut Mirjat, Wassan, \& Shaikh (2017), kekuatan dari dalam yang memengaruhi pertumbuhan wilayah dikelompokkan menjadi dua, yakni kekuatan untuk memperkuat diri sendiri (self reinforce) dan kekuatan yang membatasi pertumbuhan (self limit). Berdasarkan hal tersebut, maka Kawasan Sanglah termasuk dalam self reinforce. Hal ini karena penyebab dari pertumbuhan wilayah di Kawasan Sanglah dipengaruhi oleh adanya keterkaitan antar kegiatan di suatu wilayah. Perubahan tertentu dalam tingkat kegiatan di wilayah tersebut akan menimbulkan perubahan lebih lanjut dan memengaruhi lingkup kegiatan lainnya (Christiawan, 2019). 
Berdasarkan sebarannya, dari hasil amatan di lapangan, pengemis di Kawasan Sanglah akan mengunjungi objek satu menuju objek lainnya dimulai dari pukul 07.00 wita. Secara umum, pengemis di Kawasan Sanglah akan mengakhiri kegiatan mengemisnya pada pukul 16.00 wita. Namun demikian, terdapat beberapa pengemis yang masih menjalankan aktivitasnya hingga petang (sampai Maghrib). Berdasarkan polanya, terdapat beberapa pola yang dibentuk pengemis di Kawasan Sanglah. Mereka tersebar di beberapa titik di kawasan tersebut. Berdasarkan hasil observasi, peneliti menyimpulkan bahwa cakupan wilayah pengemis di Kawasan Sanglah dibagi atas beberapa klaster. Klasterklaster tersebut berupa klaster permukiman, pertokoan, tempat ibadah, perdagangan, dan fasilitas pelayanan kesehatan. Hal ini senada dengan teori dari Amin, Priyono, Hidayah, \& Syahputra (2017) yang menyatakan bahwa pertimbangan pemilihan lokasi mengemis dipengaruhi oleh jarak. Semakin dekat jarak antara lokasi mengemis dengan daerah tinggal, maka akan semakin efisien dari segi waktu, biaya, dan tenaga. Beberapa lokasi yang menjadi sasaran pengemis umumnya berupa kompleks pertokoan, permukiman, dan terminal. Berdasarkan klasterisasi tersebut, secara umum sebaran spasial pengemis di Kawasan Sanglah diabstraksikan melalui peta persebaran pengemis di Kawasan Sanglah yang terdapat dalam Gambar 2.

Berdasarkan Peta pada Gambar 2, hampir sebagian besar bangunan di Kawasan Sanglah yang bukan permukiman berfungsi sebagai tempat usaha, baik itu berupa toko, supermarket/ swalayan, hotel, rumah makan, salon, bioskop, bank, dan lain-lain. Hal ini juga senada dengan lokasi kunjungan pengemis lain selain di Kawasan Sanglah. Berdasarkan penelitian terdahulu, Thomassen (2015) menyebutkan bahwa berdasarkan objek kunjungan pengemis di Roma, mereka akan banyak terlihat di gereja, supermarket, minimarket, sekolah, ATM, dan toko majalah. Senada dengan hal Thomassen, dalan penelitian Mirjat et al. (2017) menyebutkan bahwa pengemis di Hyderabad umumnya akan terdapat rumah makan, supermarket, taman rekreasi, tempat ibadah, lembaga pendidikan, stasiun, bank. Berdasarkan hal tersebut, secara umum bahwa karakteristik lokasi mengemis pengemis berada di pusat keramaian.

Terdapat beberapa objek yang dijadikan pengemis untuk memulai aktivitasnya. Ada yang memulai dari klaster perdagangan terlebih dahulu. Objek-objek yang masuk pada klaster ini adalah berupa pasar dan rumah makan. Setelah itu dilanjutkan pada klaster permukiman, dilanjutkan ke klaster pertokoan, kemudian terakhir di klaster tempat ibadah. Pada beberapa pola, beberapa pengemis memiliki cakupan wilayah yang berbeda antara satu pengemis dengan pengemis lainnya. Namun demikian, apabila dilakukan analisis terhadap objek-objek kunjungan, masing-masing cakupan wilayah pengemis yang berbeda tersebut memiliki karakteristik yang hampir sama. Pusatpusat keramaian di Kawasan Sanglah memang tidak hanya berpusat pada satu titik saja, misalnya pusat pertokoan. Pusat pertokoan di Kawasan Sanglah terdiri dari tiga pusat, yakni Pertokoan Teuku Umar, Pertokoan Diponegoro, dan Pertokoan Gajah Mada. Tiga pertokoan tersebut juga menjadi salah satu dari terbentuknya pola sebaran pengemis di Kawasan Sanglah.

Hal ini senada dengan pendapat dari Amin et al. (2017) yang menyatakan bahwa pengemis akan lebih memilih deretan kompleks pertokoan karena pendapatan cenderung akan lebih tinggi pada cluster tersebut. Hal ini karena di pertokoan merupakan tempat usaha dan tidak jauh dari pangkalan angkutan kota. 


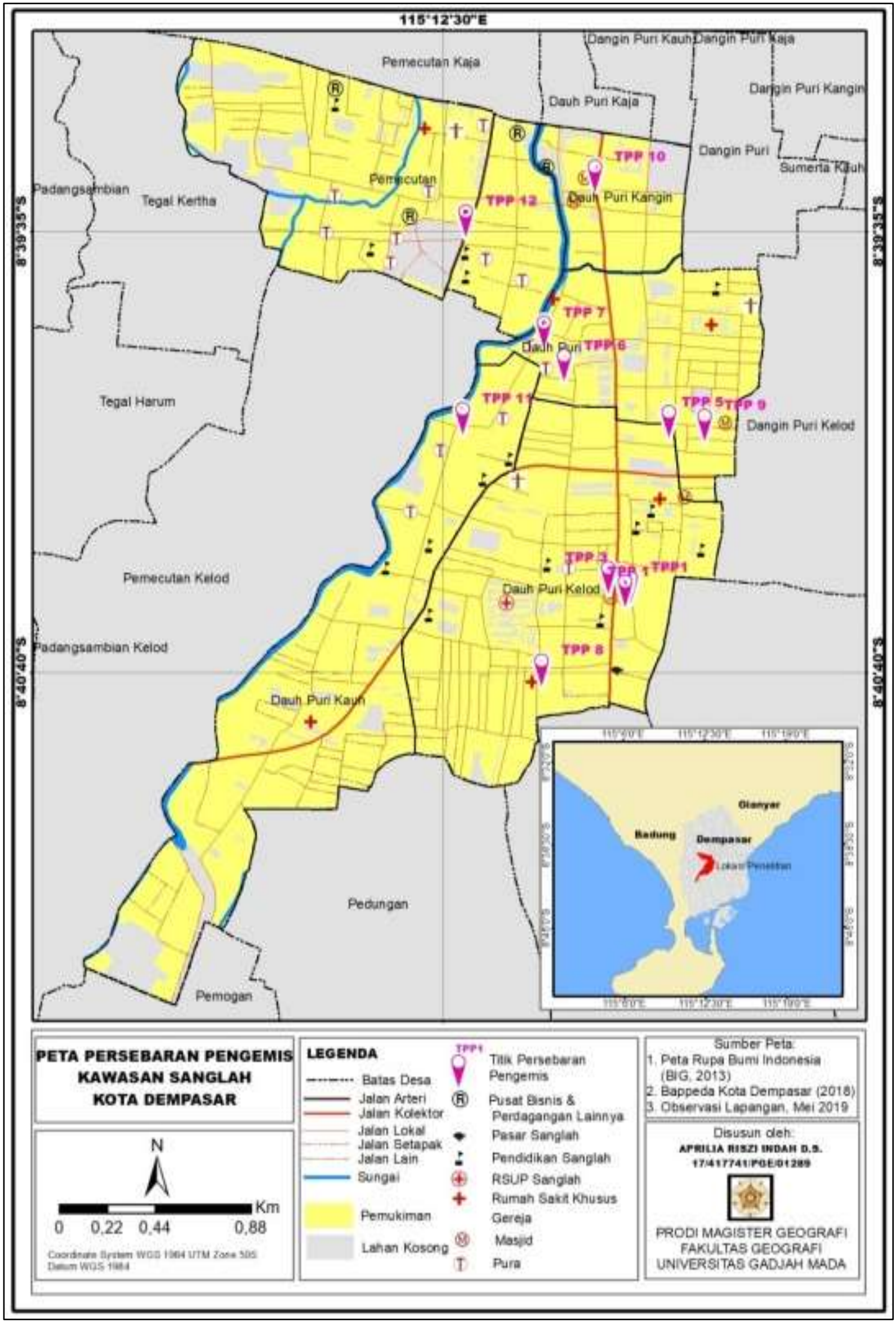

Gambar 2. Peta Persebaran Pengemis di Kawasan Sanglah Kota Denpasar 
Kepentingan dari pemilihan lokasi mengemis berdasarkan pendapat dari Amin et al. (2017) secara general ditekankan pada lokasi-lokasi yang memiliki nilai strategis tinggi, membentuk cluster-cluster tertentu, beraglomerasi, sehingga efisien dari segi waktu, tenaga, dan biaya (menuju dan kembali ke tempat tinggal). Berdasarkan deskripsi tersebut, berikut diabstraksikan pola persebaran pengemis yang divisualisasi dalam bentuk peta rute perjalanan pengemis di Kawasan Sanglah yang disajikan dalam Gambar 3.

Peta pada Gambar 3 menjelaskan bahwa terdapat tiga pola pengemis di Kawasan Sanglah berdasarkan rute perjalanannya. Pola pertama titik sentralnya berada pada kawasan Pertokoan Diponegoro. Pola kedua, titik sentralnya berada pada kawasan Pertokoan Gadjah Mada, dan pola terakhir titik sentralnya berada pada kawasan Pertokoan Teuku Umar. Hasil pola yang didapat ini merupakan hasil plotting terhadap masing-masing objek kunjungan pengemis dengan mengikuti arah dan rute perjalanan mereka. Representasi dari hasil plotting tersebut selanjutnya dibuat dalam bentuk peta sehingga dapat diketahui bagaimana persebaran mereka di Kawasan Sanglah. Masing-masing objek kunjungan memiliki fungsi sebagaimana yang disebutkan sebelumnya. Khusus pada satu pola rute perjalanan pengemis, terdapat garis hijau dalam legenda peta yang mana pada pola tersebut pengemis menaiki bus berupa Isuzu untuk melanjutkan ke destinasi berikutnya. Hal tersebut dilakukan untuk mengefesiensikan waktu dan juga tenaga. Biaya yang dikeluarkan pengemis untuk menaiki Isuzu tersebut adalah sebesar Rp2.000,--.

Kekhasan spasial dari distribusi pengemis di Kawasan Sanglah ini adalah bahwa pengemis mampu membuat pola dengan pertimbangan waktu dan objek kunjungan secara terstruktur. Contohnya, pengemis akan terlebih dahulu mengunjungi objek-objek kunjungan yang masuk dalam klaster perdagangan seperti pasar dan rumah makan. Hal ini didasari pada pertimbangan bahwa klaster tersebut merupakan pusat-pusat pemenuhan kebutuhan primer, sehingga akan buka lebih pagi. Pengemis selanjutnya akan mengunjungi objek-objek kunjungan yang berada pada klaster pertokoan seperti toko mebel, toko minyak wangi, toko kain, toko emas yang notabene merupakan pusat-pusat kebutuhan sekunder dan tersier sehingga jam buka nya lebih siang. Saat menyusuri objek-objek tersebut, mereka akan mengunjungi permukiman yang mereka lewati. Terakhir, mereka akan berada di tempat-tempat ibadah atau di sekitar toko oleh-oleh atau di minimarket saat siang hari.

Berdasarkan uraian pembahasan tersebut, secara keseluruhan dapat disederhanakan terkait dengan sebaran spasial pengemis di Kawasan Sanglah Kota Denpasar. Mengacu pada data dari Dinas Sosial Kota Denpasar sampai dengan tahun 2019, Kecamatan Denpasar Barat masih menjadi kecamatan paling ramai dikunjungi oleh pengemis (sesuai dengan data razia pengemis di Kota Denpasar). Hal ini karena Kecamatan Denpasar Barat merupakan kecamatan yang memiliki akses sarana prasarana publik yang paling lengkap. Pusat pemerintahan, pusat pendidikan, pusat kesehatan, pusat kegiatan sosial dan ekonomi semuanya berada di kecamatan tersebut. Kondisi demikian tentu menjadi daya tarik tersendiri bagi pengemis karena memang mereka akan mencari lokasilokasi yang ramai dan strategis. Lebih spesifik lagi, pengemis di Kecamatan Denpasar Barat paling banyak berada di Kawasan Sanglah. Kawasan Sanglah dan sekitarnya merupakan kawasan yang memiliki fungsi sebagai pusat kegiatan ekonomi, pendidikan tinggi, dan pelayanan kesehatan skala wilayah. Kawasan Sanglah sendiri memiliki kestrategisan lokasi yang sangat mendukung bagi pengemis untuk mengemis di kawasan tersebut. 
Pengembangan Sentra Industri Kecamatan Tempuran Berdasarkan Indeks Spesialisasi dan Konsentrasi Spasial di Kabupaten Magelang/ Andi Panca Putra, Andri Kurniawan, Sri Rahayu Budiani

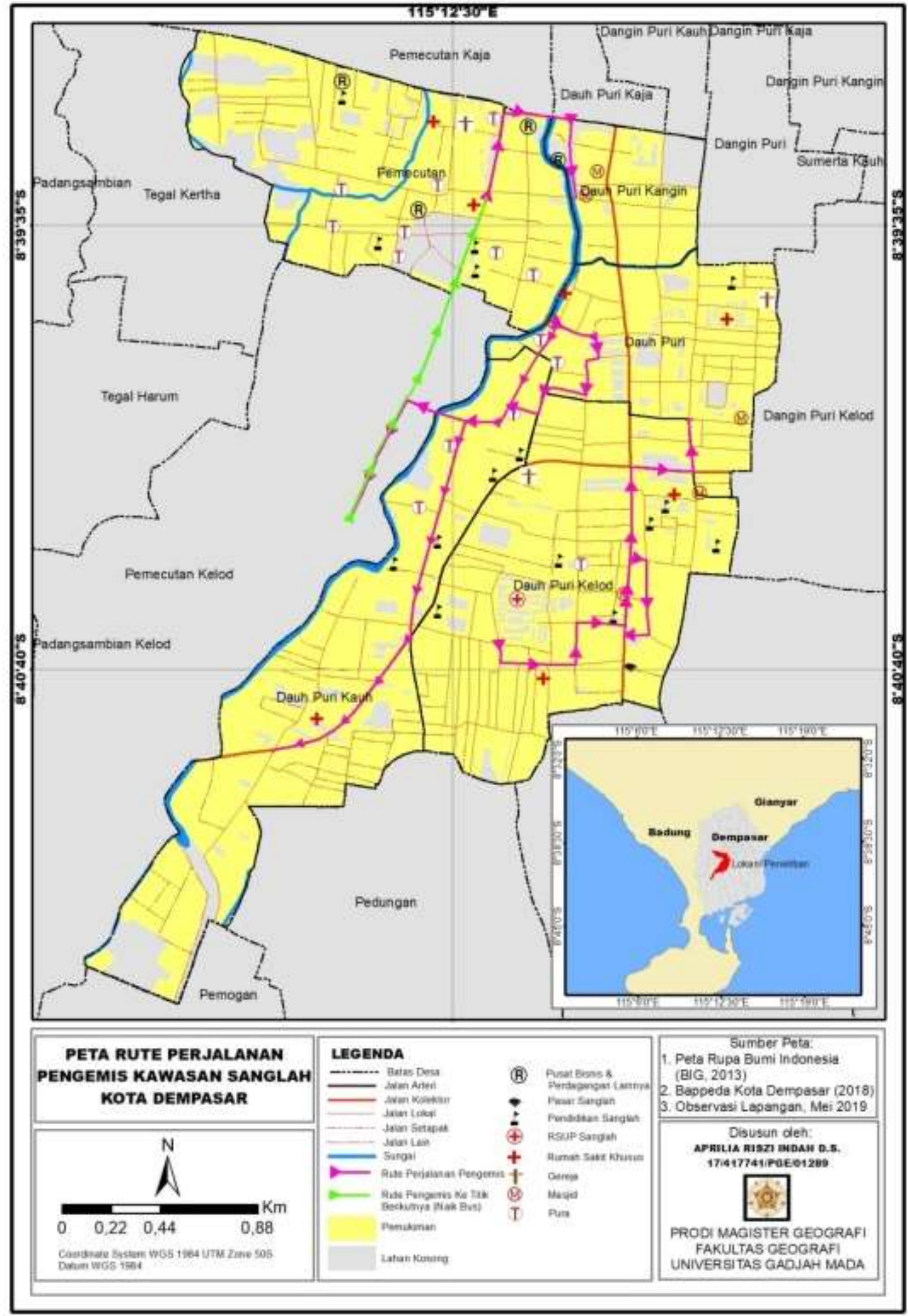

Gambar 3. Peta Rute Perjalanan Pengemis di Kawasan Sanglah Kota Denpasar 
Distribusi sebaran pengemis di Kawasan Sanglah berada pada beberapa pusat yang membentuk pola sebarannya. Berdasarkan hasil observasi secara berkala, dapat disimpulkan bahwa pola sebaran pengemis di Kawasan Sanglah terdiri dari tiga rute, yang mana masingmasing memiliki pusat sebaran. Masingmasing pusat sebaran berada di Pertokoan Diponegoro, Pertokoan Teuku Umar, dan Pertokoan Gajah Mada. Adapun yang menjadi objek kunjungan pengemis di Kawasan Sanglah berupa kawasan perdagangan, pertokoan, permukiman, fasilitas kesehatan, dan sarana ibadah.

\section{Kesimpulan}

Berdasarkan hasil pemaparan terkait analisis sebaran spasial pengemis di Kawasan Sanglah Denpasar, adapun kesimpulan dari penelitian ini adalah: berdasarkan sebarannya, terdapat beberapa klaster di Kawasan Sanglah yang dijadikan sebagai lokasi mengemis. Klaster-klaster tersebut berupa kawasan permukiman, pertokoan, perdagangan, fasilitas pelayanan kesehatan, dan sarana ibadah. Pada beberapa pola, beberapa pengemis memiliki cakupan wilayah yang berbeda antara satu pengemis dengan pengemis lainnya. Pusat-pusat keramaian di Kawasan Sanglah memang tidak hanya berpusat pada satu titik saja, misalnya pusat pertokoan. Pusat pertokoan di Kawasan Sanglah ada di sekitar Jalan Teuku Umar, Jalan Diponegoro, dan juga Jalan Gajah Mada. Kekhasan spasial dari distribusi pengemis di Kawasan Sanglah ini adalah bahwa pengemis mampu membuat pola dengan pertimbangan waktu dan objek kunjungan secara terstruktur. Contohnya, pengemis akan terlebih dahulu mengunjungi objek-objek kunjungan yang masuk dalam klaster perdagangan seperti pasar dan rumah makan. Hal ini didasari pada pertimbangan bahwa klaster tersebut merupakan pusat-pusat pemenuhan kebutuhan primer, sehingga akan buka lebih pagi. Pengemis selanjutnya akan mengunjungi objek-objek kunjungan yang berada pada klaster pertokoan seperti toko mebel, toko minyak wangi, toko kain, toko emas yang notabene merupakan pusat-pusat kebutuhan sekunder dan tersier sehingga jam buka nya lebih siang. Saat menyusuri objek-objek tersebut, mereka akan mengunjungi permukiman yang mereka lewati. Terakhir, mereka akan berada di tempat-tempat ibadah atau di sekitar toko oleh-oleh atau di minimarket saat siang hari. Berdasarkan temuan tersebut, diharapkan hal ini bisa dijadikan sebagai bahan masukan bagi dinas terkait dalam membina pengemis yang telah diketahui pola mengemisnya.

\section{Daftar Pustaka}

Ahmad, M. (2012). Strategi Kelangsungan Hidup Gelandangan-Pengemis (Gepeng). Jurnal Penelitian, 7(2), 5162.

Amin, C., Priyono, U., Hidayah, N., \& Syahputra, B. M. (2017). Analisis Karakteristik dan Mobilitas Pengemis di Kota Salatiga. In Urecol Proceeding. Yogyakarta: Universitas Gadjah Mada.

Anggriana, T. M., \& Noviyanti, K. D. (2016). Identifikasi Permasalahan Gelandangan dan Pengemis di UPT Rehabilitasi Sosial Gelandangan dan Pengemis. INQUIRY: Jurnal IImiah Psikologi, 7(1), 1-10.

BPS Kota Denpasar. (2017). Kota Denpasar Dalam Angka 2017

Christiawan, P. I. (2019). Tipe Urban Sprawl dan Eksistensi Pertanian di Wilayah Pinggiran Kota Denpasar. Jurnal Wilayah Dan Lingkungan, 7(2).

Fu'adah, L., Astuti, T. M. P. A., \& Utomo, C. B. U. (2017). Tindakan Sosial Tunawisma terhadap Strategi Bertahan Hidup di Kota Semarang. Journal of Educational Social Studies, 6(1), 45-51.

lqbali, S. (2005). Studi Kasus Gelandangan-Pengemis (Gepeng) Di Kecamatan Kubu Kabupaten Karangasem. Universitas Udayana.

lqbali, S. (2006). Studi Kasus Gelandangan-Pengemis (Gepeng) Di Kecamatan Kubu Kabupaten Karangasem. Piramida, 1(1), 1-10.

Mirjat, A. J., Wassan, A. A., \& Shaikh, S. (2017). Beggary in Hyderabad Division: A Sociological Analysis. Grassroots, 51(2), 101-120.

Shara, A. R. I. D. (2018). Analisis 


\section{Konektivitas Wilayah di Kota \\ Denpasar. Media Komunikasi}

Geografi, 19(1), 42-50.

Sriartha, I. P., Diatmika, I. P. G., \& Putra, I.

W. K. E. (2017). Pemetaan Spasial

Daya Dukung Lahan Pertanian dan

Daya Tampung Penduduk

Kecamatan di Provinsi Bali. In Seminar Nasional Riset Inovatif 2017. Singaraja: Undiksha Press.

Yuniarti, N. (2012). Eksploitasi Anak Jalanan sebagai Pengamen dan Pengemis di Terminal Tidar oleh

Keluarga. International Journal of Indonesian Society and Culture, 4(2), 100-110.

Zukna, Pribadi, H., \& Nopianti, H. (2018). Strategi Bertahan Hidup Pengemis Tunanetra (Studi Pada Pengemis di Lampu Merah Sukamerindu). Jurnal Sosiologi Nusantara, 4(2), 85-97. 